\title{
Announcing the VII National Congress of the Portuguese Society of Neuroradiolgy (SPNR) and the XLII Annual Meeting of the Spanish Society of Neuroradiology (SENR)
}

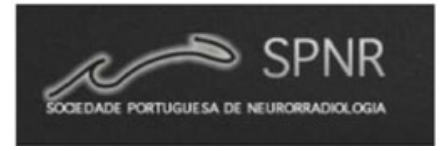

(C) Springer-Verlag Berlin Heidelberg 2013

The XLII Annual Meeting of the Spanish Society of Neuroradiology (Sociedad Española de Neuroradiología-SENR) and the VII National Congress of the Portuguese Society of Neuroradiology (Sociedade Portuguesa de NeuroradiologiaSPNR) will be held in Lisbon on October 17th to 19th, 2013.

The scientific Committee has elaborated an attractive program which included a pre-congress course focused on the advanced aspects of interventional and diagnostic neuroradiology. Reputed international speakers, as Prof. Timo Krings from University of Toronto (Canada), Prof. Vitor Mendes Pereira from University Hospital of Geneva (Switzerland), and Prof. Andrea Rossi from University of Genoa (Italy) will share their knowledge and expertise through plenary sessions. This event also include talks focus on innovated aspects and relevant topics in diagnostic and interventional neuroradiology of spine and head/neck by some of the most prominent Portuguese and Spanish neuroradiologists.
The meeting will take place in Lisbon, Portugal, one of the most enjoyable cities in Europe. It is located in the western part of the country were the river Tagus meets the Atlantic Ocean. For this reason, Lisbon is considered the city of oceans, the only capital European with sunsets on the sea. It's also one of the world's great historical cities with surprising sight and cultural treasures and its mild climate makes it an ideal year-round destination.

The Presidents of SPNR, Dr. Pedro Vilela, and SENR, Dr. Alex Rovira, on behalf of their Societies, are pleased to invite you to attend this meeting. More information will be available soon on the websites of the SENR (www.senr.org) and the SPNR (www.spnr.org).

We are waiting for you in Lisbon!

\section{Portuguese Society of Neuroradiology \\ Spanish Society of Neuroradiology}

